\title{
Thermal and mechanical properties of polyurethanes modified with $\mathbf{L}$-ascorbic acid
}

\author{
J. Kucinska-Lipka' ${ }^{1}$ I. Gubanska ${ }^{1}$ - M. Sienkiewicz ${ }^{1}$
}

Received: 10 December 2015/Accepted: 20 July 2016/Published online: 4 August 2016

(c) The Author(s) 2016. This article is published with open access at Springerlink.com

\begin{abstract}
In this study we report the thermal and mechanical properties of polyurethanes modified with ascorbic acid (AA). Ascorbic acid was used as a modifier at concentration of 1 or 2 mass $\%$. The antioxidative properties of AA may improve the biocompatibility of the obtained materials, which were designed for biomedical applications. In this paper we describe characterization of obtained unmodified and ascorbic acid modified polyurethanes with the use of following methods: dynamic mechanical analysis, thermogravimetric analysis and mechanical tests including tensile strength, elongation at break, abrasive resistance, and hardness. Results of performed studies suggests that synthesized polyurethane materials may be suitable candidates for biomedical applications such as tissue scaffolds or implants, where required tensile strength is in the range of $1-14 \mathrm{MPa}$ and elongation at break is approximately in the range of $100-380 \%$.
\end{abstract}

Keywords Polyurethane $\cdot$ Ascorbic acid · Biomedical field - Thermomechanical properties - Thermal analysis . Mechanical properties

\section{Introduction}

Polyurethanes (PURs) are synthetic polymers of unique properties, which are directly related to their two-phase microstructure consisting of hard and soft segments. Hard

J. Kucinska-Lipka

juskucin@pg.gda.pl

1 Department of Polymer Technology, Faculty of Chemistry, Gdansk University of Technology, Narutowicza St. 11/12, 80-233 Gdansk, Poland segments, derived from diisocyanates and low molecular weight chain extenders, possess high glass transitions. On the other hand, soft segments formed by polyols have low glass transitions [1-5]. Polyurethanes are commonly used medical devices such as catheters, wound dressings, drug delivery systems, artificial heart valves, vascular grafts, nerve implants, and tissue scaffolds [6]. These types of polyurethanes have to meet strict requirements of thermal, mechanical, physicochemical, and biological properties of biomedical materials. PURs have revealed also suitable biocompatibility, hemocompatibility, and biodegradability (if desired). In order to improve the thermal properties of polyurethanes, researchers modify them mostly by incorporating nanoparticles $[7,8]$ and proteins [9] or by changing the amount and type of monomers used for their synthesis [10]. To improve the mechanical properties of polyurethanes, often other polymers are used as modifiers for example epoxy resins [11-14]. Polyurethanes prepared with the use of suitable raw materials are biocompatible and may be biodegradable - this can be designed dependently on material destination $[15,16]$. Tailoring of polyurethane properties like biodegradability or biocompatibility may be performed in many different ways but commonly biologically active substances are incorporated into the polyurethane chains [17]. The suitable choice of biologically active substance may improve the biocompatibility and/or biodegradability of final PUR product, but it can also influence on its mechanical performance and thermal properties. One of such bioactive substance may be ascorbic acid. AA is commonly known as vitamin C. It is used as a pharmaceutical agent, cosmetic ingredient, and dietary supplement $[18,19]$. AA is an important antioxidant, which can reduce superoxides, hydroxyl radicals, hypochlorous acid, and other radicals and oxidants present in physiological environment. 
Moreover, AA accumulates in the immune defense cells of the human body, such as lymphocyte B and lymphocyte T, and thus improves the resistance of human body against diseases. Ascorbic acid has large impact on tissues regeneration due to improving collagen synthesis [20], which is a component of the primary extracellular matrix (ECM) [21], which supports cells attachment, growth, and proliferation [22]. Some literature data show that researchers took an attempt to incorporate AA into the polyurethane structure to improve the material biocompatibility and biodegradability [23, 24].

Pharmaceutical supplements and products containing AA are often subjected to thermal treatment during preparation, processing, and storage [25-29]. In case of using AA as a polyurethane chain modifier, it would be also subjected to thermal treatment such as polyurethane synthesis and curing (both carried out at $80^{\circ} \mathrm{C}$ ). Thermal stability is of particular interest, because of the thermal decomposition kinetics studies, which may lead to improvement in ascorbic acid stability, which is important especially considering the context of pharmaceuticals, food products [18], and recently medical devices, modified with ascorbic acid [23, 24]. In the literature are available degradation studies of ascorbic acid, carried out under different conditions, such as in different solvents [30], in steam [31], in food [20], under oxygenated conditions [32] and under inert conditions [33]. To simulate physiological environment or storage conditions, researchers performed studies under invariable temperature and below $100{ }^{\circ} \mathrm{C}$. Due to our knowledge there are no literature data determining DMA and TG properties of polyurethanes, obtained with the use of aliphatic 1,6-hexamethylene diisocyanate (HDI) and modified with ascorbic acid for medical applications.

References report a number of instrumental methods, such as differential scanning calorimetry, differential thermal analysis, and thermogravimetric analysis, which may be used to determine the study of decomposition kinetics [18] and degradation products of ascorbic acid [31, 32, 34]. Jingyan et al. investigated the thermal behavior of dry and solid ascorbic acid in a wide temperature range from -25 to $800{ }^{\circ} \mathrm{C}$. In order to determine the ascorbic acid decomposition kinetics, they used the TG-FTIR technique, where samples were heated from 25 to $800{ }^{\circ} \mathrm{C}$, at a rate of $20{ }^{\circ} \mathrm{C} \min ^{-1}$, under nitrogen gas atmosphere. The resulted TG curve showed that dry solid AA is thermally stable and does not decompose until $191{ }^{\circ} \mathrm{C}$ [34].

The decomposition mechanism of ascorbic acid was determined as very complex. It is due to the many possible degradation pathways and over 200 different end-products, which have been reported in literature data. Experimental conditions such as solvent $\mathrm{pH}$, temperature, oxygen, catalyzer, and enzyme may influence the ascorbic acid degradation pathway [34]. Moreover, the degradation of solid AA is believed to follow at the different path than in solution. When $5 \% \mathrm{v} / \mathrm{w}$ moisture was present in a solid ascorbic acid sample, the discoloration was observed, from white to dark brown [31]. Studies on decomposition kinetics of vitamin $\mathrm{C}$ in various food products under different storage and processing conditions revealed that decomposition of AA follows with first-order kinetics [25-29]. Jingyan et al. also proposed the explanation of three indicated degradation stages of solid ascorbic acid. In the first stage of decomposition $\left(191-268^{\circ} \mathrm{C}\right)$ main gases evolved were: $\mathrm{H}_{2} \mathrm{O}, \mathrm{CO}_{2}, \mathrm{CO}$, but mostly formaldehyde. These gases can only be formed by AA molecular fracture or intermolecular reaction in high-purity nitrogen atmosphere (absence of $\mathrm{O}_{2}$ ). At the second stage $\left(268-504{ }^{\circ} \mathrm{C}\right.$ ), the main evolved gases were $\mathrm{CO}_{2}$ and $\mathrm{CO}$ and at the third stage $\left(504-800{ }^{\circ} \mathrm{C}\right) \mathrm{CO}$ and $\mathrm{CH}_{4}$. Jingyan et al. concluded that the main decomposition process occurred at the first and second stage. In the first stage, decarboxylation and dehydration were the main decomposition reactions. In the second stage main reactions were decarboxylation and decarbonylation. At the third stage, only slow carbonization process was observed. Some publications reports that the decomposition of AA leads to furan derivatives, in which furfural was considered as a main product $[31,34]$.

In this paper we report the DMA, TG, and mechanical characteristics of ascorbic acid-modified polyurethanes. Materials were obtained with the use of oligomeric $\alpha, \omega-$ dihydroxy(ethylene-butylene adipate) (dHEBA) polyol which formed the soft segments in obtained PURs and 1,6hexamethylene diisocyanate (HDI) and 1,4-butanediol chain extender which formed hard segments. PURs were synthesized by the standard two step pre-polymerization method. Ascorbic acid, used as PUR modifier, was added in the amount of 1 or 2 mass\%. Its usage was reasonable, in the design of biomedical polyurethanes, due to its antioxidative properties and significant influence on tissues regeneration. This is important for materials used as tissue scaffolds, particularly in cardiac surgery. The influence of such biologically active substance like ascorbic acid on obtained PURs thermal properties remains interesting. Obtained PURs were characterized with the use of the following methods: dynamic mechanical analysis (DMA), thermogravimetric analysis (TG), and mechanical tests including tensile strength, elongation at break, abrasion resistance, and hardness.

\section{Experimental}

\section{PUR materials}

This article describes the properties of PURs synthesized with the use of oligomeric $\alpha, \omega$-dihydroxy(ethylene-butylene 
adipate) (dHEBA) polyol (trade name Polios 55/20; Purinova, Poland), aliphatic 1,6-hexamethylene diisocyanate (HDI) (Sigma-Aldrich, Poland) and 1,4-butanediol (BDO) (POCH, Poland). The molar ratio of isocyanate groups to hydroxyl groups of the chain extender BDO in the PURs was used in the following manner $(\mathrm{NCO} / \mathrm{OH}=0.9: 1 ; 1: 1$; 1.05:1). Dibutyltin dilaurate (DBTDL), a commonly used catalyst in biomedical polyurethanes synthesis [25-27], was used at a concentration of 0.5 mass $\%$ After tensile strength evaluation, unmodified PURs samples, prepared at molar ratio of $\mathrm{NCO}: \mathrm{OH}$ equal 1:1, were selected for further ascorbic acid modifications (1 or 2 mass \%). Full description of performed PUR synthesis was described in our previous work [35], where FTIR and HNMR spectroscopy confirmed that chemical structure and composition of PUR was achieved.

\section{Techniques}

\section{Mechanical properties}

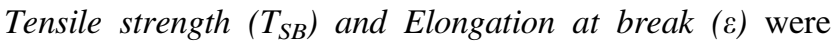
examined with the use of the universal testing machine Zwick and Roell Z020 according to PN-EN-ISO 1799:2009. The test was performed at room temperature with the use of six PUR samples. The crosshead speed was of $300 \pm 5 \mathrm{~mm} \mathrm{~min}^{-1}$. Sample dimensions are presented in Fig. 1.

Hardness was studied with the use of the Shore method according to PN-EN ISO 868:2004. The measurement of hardness was done with a digital hardness meter Shore A type (Zwick/Roell, type 3101/3131). The needle placed at one end of the meter was pressed to a round sample $(\varnothing 50 \mathrm{~mm}$ ) of obtained PURs. The resistance of the material to the applied force was measured. Obtained data were presented with Shore degree ( $\left.{ }^{\circ} \mathrm{Sh} \mathrm{A}\right)$. Number of performed hardness measurements was 10 on each side of PUR.

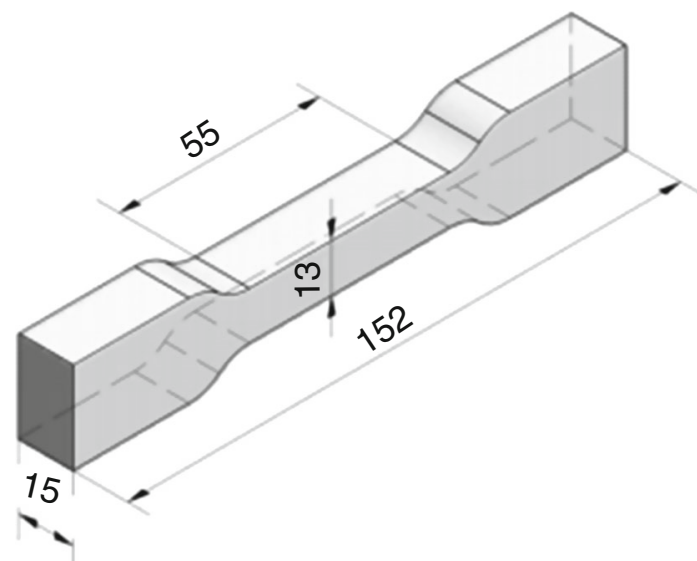

Fig. 1 Dumbbell-shaped sample used for the tensile strength and elongation at break test
Abrasion resistance of PUR samples was examined with the use of a Schopper-Schlobach apparatus APGi according to the PN 75 C 04235. Roller-shaped samples with dimensions of $16 \mathrm{~mm}$ in diameter and $6 \mathrm{~mm}$ thick were prepared with the use of a normalized punching die. The cylinder of the Schopper-Schlobach apparatus has diameter of $15 \mathrm{~cm}$ and was covered with emery paper of no. 60 . Its rotating speed was $40 \mathrm{rpm}$. The sample was placed into the gripper and, by using a micrometer screw, was set to stick out from the gripper for $2 \mathrm{~mm}$. Sample was pressed to the roller with $1-\mathrm{kg}$ force and relative displacement of emery paper and the sample was of $40 \mathrm{~m}$. Before and after examination, samples were weighted with accuracy to $0.001 \mathrm{~g}$. The percentage of volume loss was calculated by the formula (1). Ten samples of unmodified and ascorbic acid-modified PUR were studied.

$V=\frac{\left(m_{1}-m_{2}\right) \times 0.2}{\rho \times \Delta m_{\mathrm{w}}}$

$m_{1}$-sample's mass before abrasion test, $\mathrm{g} ; m_{2}$-sample's mass after abrasion test, $\mathrm{g} ; \Delta m_{\mathrm{w}}$ - the average mass loss of three reference samples, $g$; 0.2 -theoretical mass loss of the rubber sample, $\mathrm{g} ; \rho$-density of the sample, $\mathrm{g} \mathrm{cm}^{-3}$

Dynamic mechanical analysis (DMA) was performed with the use of TA Instruments Q800 DMA analyzer. A beam-shaped sample was placed in the testing machine. The sample, placed in the holder, through the mandrel, was subjected to sinusoidal impact strength with constant amplitude of 1 and $10 \mathrm{~Hz}$ in three-point bending mode. The sample was heated at a rate of $4{ }^{\circ} \mathrm{C} \min ^{-1}$ from -100 to $100{ }^{\circ} \mathrm{C}$. During the test liquid nitrogen was used as cooling medium in the chamber.

Thermogravimetric analysis (TG) was performed on a Mettler-Toledo TG analyzer in the temperature range from 0 to $600{ }^{\circ} \mathrm{C}$ with heating rate of $1{ }^{\circ} \mathrm{C} \mathrm{min}^{-1}$. Liquid nitrogen was used as the cooling medium in the chamber. Sample mass was $10 \mathrm{mg}$ and it was placed in aluminum crucibles.

\section{Polyurethane symbols and their meaning}

Table 1 shows symbols used to mark the obtained unmodified and modified with ascorbic acid (1 or 2 mass\%) polyurethanes with their brief explanation. The detailed description of the PUR synthesis, raw materials ratios and synthesis conditions, were described in our previous work [33].

\section{Results and discussion}

\section{Mechanical properties}

The results of mechanical tests are presented in Table 2 . The unmodified polyurethanes had slightly higher tensile 
Table 1 Symbols of obtained unmodified and modified polyurethanes with brief explanation

\begin{tabular}{|c|c|}
\hline Symbol & Explanation \\
\hline PUR-1/HDI/AA0 & $\begin{array}{l}\text { PUR-1_polyurethane obtained in molar ratio of } \mathrm{NCO}: \mathrm{OH}=1: 1 \\
\text { HDI-diisocyanate used for PUR synthesis } \\
\text { AA0_-PUR not modified with ascorbic acid }\end{array}$ \\
\hline PUR-1/HDI/AA1 & $\begin{array}{l}\text { PUR-1—polyurethane obtained in molar ratio of } \mathrm{NCO}: \mathrm{OH}=1: 1 \\
\text { HDI-diisocyanate used for PUR synthesis } \\
\text { AA1-PUR modified with } 1 \text { mass } \% \text { of ascorbic acid }\end{array}$ \\
\hline PUR-1/HDI/AA2 & $\begin{array}{l}\text { PUR-1—polyurethane obtained in molar ratio of } \mathrm{NCO}: \mathrm{OH}=1: 1 \\
\text { HDI-diisocyanate used for PUR synthesis } \\
\text { AA2-PUR modified with } 2 \text { mass } \% \text { of ascorbic acid }\end{array}$ \\
\hline
\end{tabular}

strength $(7.2 \pm 0.2 \mathrm{MPa})$ and elongation at break $(172 \pm 2 \%)$ than the modified samples (Table 2). In case of modified polyurethanes, comparable tensile strength was observed for samples modified with 1 and 2 mass $\%$ of ascorbic acid (5.1 \pm 0.2 and $5.8 \pm 0.2 \mathrm{MPa}$, respectively). The same relationship was observed in case of elongation at break of obtained modified PURs (PUR1/HDI/AA2 $=169 \pm 1 \%$, PUR-1/HDI/AA2 $=161 \pm 2 \%$, respectively). The introduction of vitamin $\mathrm{C}$ slightly decreased mechanical properties of modified PURs. It is due to the fact that AA was only partially incorporated into the PUR chain and its unreacted remains stayed enclosed in PUR matrix. Molecules of AA in PUR matrix acts as an inactive filler, which cause decrease in the mechanical properties of obtained modified PURs [35].

In the literature data there are two more works related to polyurethanes modified with ascorbic acid [21, 34]. Only Cetina-Diaz et al. studied mechanical and thermal properties of PURs, in which ascorbic acid was used as filler. PURs were obtained with the use of polycaprolactone, $4,4^{\prime}$ methylene bis(cyclohexyl diisocyanate), 1,4-butandiol, and stannous octoate as a catalyzer. Determined tensile strength of such ascorbic acid-filled polyurethanes was $47.75 \pm 16.70 \mathrm{MPa}$, which is significantly higher than in case of PURs described in this paper. In the literature data there are many reports of biomedical PURs mechanical studies [37]. For example Dey et al. performed urethanedoped polyesters of tensile strength in the range of $14.6 \pm 1.0-41.07 \pm 6.9 \mathrm{MPa}$ and elongation at break of $337.0 \pm 6.0 \%$ [36]; Guan et al. obtained poly(ester urethane)ureas and poly(ether-ester urethane) ureas with the use of polycaprolactone polyester or bloc copolymer of poycaprolactone and polyethylene glycol soft segments and 1,4-diisocyanatobutane and putrescine derived hard segments. Tensile strength of obtained by Guan et al. PURs was $0.97-1.64$ and $0.59-1.68 \mathrm{MPa}$, respectively, to the mentioned materials. Elongation at break of these materials was of $150 \%$ [38]. On the other hand, Zhang et al. synthesized crosslinked urethane-doped polyester elastomers (CUPOMC), which were obtained in the synthesis of photocrosslinkable poly(octamethylene maleate citrate) (POMC) prepolymers with 1,6-hexamethylene diisocyanate (HDI). Tensile strength of obtained materials was in the range of $0.73 \pm 0.12-10.91 \pm 0.64 \mathrm{MPa}$ and elongation at break in the range of 72.9 $\pm 9.1-300 \pm 22 \%$. In comparison with these data, we conclude that the obtained unmodified and ascorbic acid-modified polyurethanes possessed suitable mechanical properties for biomedical applications.

Unmodified polyurethanes had slightly higher hardness $\left(90.1 \pm 0.3^{\circ} \mathrm{Sh} \mathrm{A}\right)$ in comparison with modified polyurethanes (PUR-1/HDI/AA1 $=87 \pm 0.2{ }^{\circ} \mathrm{Sh}$ A and PUR1/HDI/AA2 $=86 \pm 0.3{ }^{\circ} \mathrm{Sh} \mathrm{A}$, respectively) (Table 2). The modification caused a slight decrease in hardness to $86 \pm 0.3{ }^{\circ} \mathrm{Sh}$ A for polyurethanes modified with 2 mass $\%$ of ascorbic acid. Little volume loss was observed for unmodified polyurethane samples $\left(0.2 \pm 0.1 \mathrm{~cm}^{3}\right)$ (Table 2). The similar value of volume loss was noted for PURs modified with 1 mass $\%$ of AA $\left(0.3 \pm 0.1 \mathrm{~cm}^{3}\right)$. A little difference of volume loss, in comparison with

Table 2 Mechanical properties of obtained unmodified and ascorbic acid modified PURs

\begin{tabular}{lccc}
\hline Mechanical properties/symbol & PUR-1/HDI/AA0 & PUR-1/HDI/AA1 & PUR-1/HDI/AA2 \\
\hline Tensile strength/MPa & $7.2 \pm 0.2$ & $5.1 \pm 0.2$ & $5.8 \pm 0.2$ \\
Elongation at break/\% & $172 \pm 2$ & $161 \pm 2$ & $169 \pm 1$ \\
Hardness $/{ }^{\circ}$ Sh A & $90.1 \pm 0.3$ & $87 \pm 0.2$ & $86 \pm 0.3$ \\
Abrasion $/ \mathrm{cm}^{3}$ & $0.2 \pm 0.1$ & $0.3 \pm 0.1$ & $0.6 \pm 0.1$ \\
\hline
\end{tabular}


Fig. 2 Loss modulus (a), storage modulus (b) and tangent of an angle $\delta$ (c) indicated for unmodified and ascorbic acid modified polyurethanes
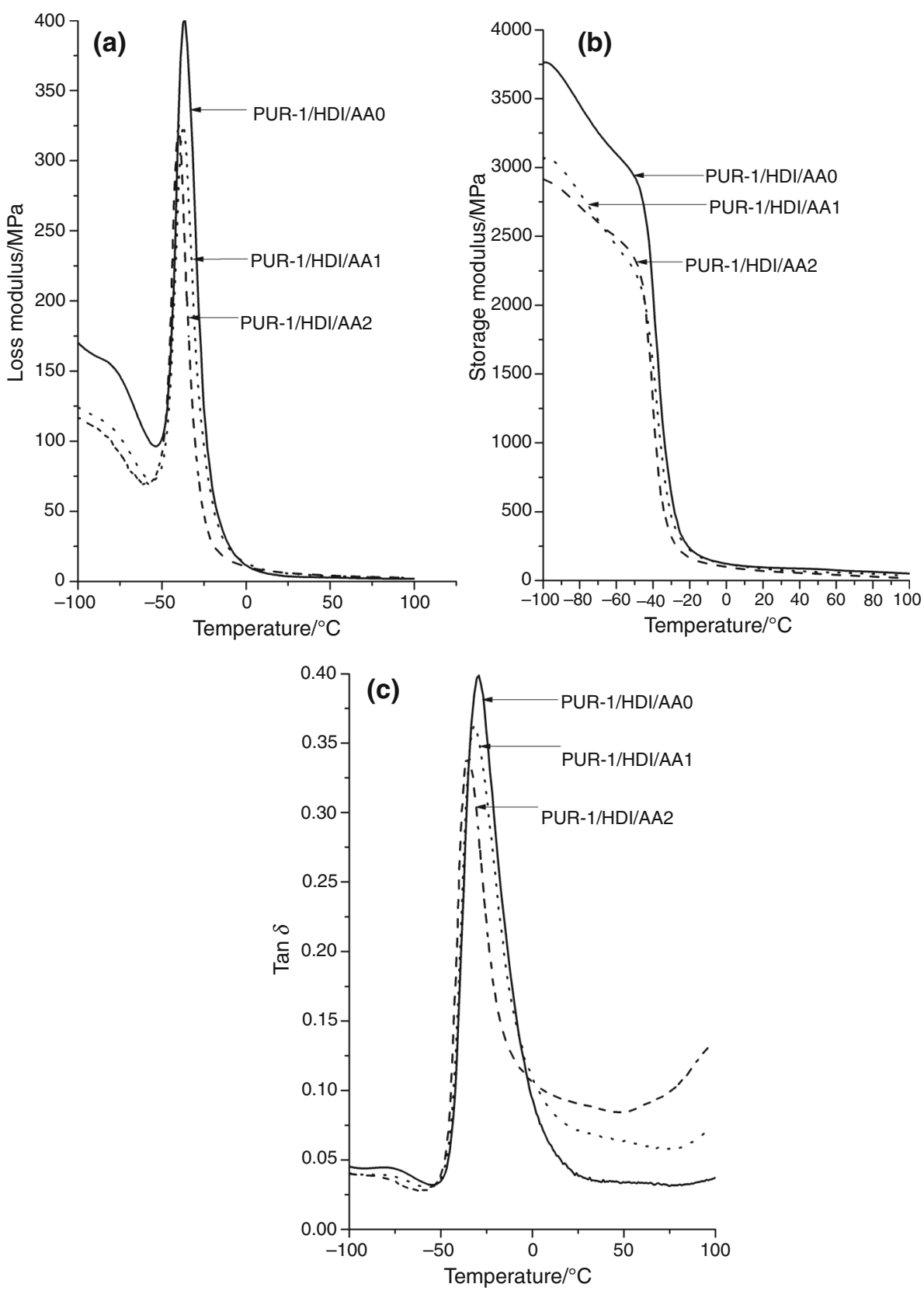

unmodified samples, was observed for polyurethanes modified with 2 mass\% of ascorbic acid $\left(0.6 \pm 1 \mathrm{~cm}^{3}\right)$. In summary, the abrasion resistance, of the obtained polyurethanes, decreases with the increase in ascorbic acid amount. This conclusion may be related to the results of the performed hardness test for both unmodified and ascorbic acid modified samples.

\section{Dynamic mechanical analysis (DMA)}

The DMA results are presented in Fig. 2 and in Table 3. It was observed that tangent of an angle $\delta$ (the tangent of the phase angle between the modulated strain and the modulated stress; see Fig. 2c) slightly decreased with the increase in ascorbic acid content in the PUR matrix (Table 3). Tan $\delta$ is also called damping coefficient, which shows the relation between filler and the PUR matrix. In this case it looks like ascorbic acid showed well interactions with the PUR matrix, because with the increase in the amount of ascorbic acid in PUR matrix the damping coefficient decreases. In such situation it can be concluded that AA acts as an inactive filler, which did not influence physical crosslinks of the PUR material. On the other hand, the decrease in the loss modulus (Fig. 2a) and storage modulus may confirm that obtained AA modified PURs did not have crosslinked structure. 
Table 3 Values of loss modulus, storage modulus and damping coefficient indicated for unmodified and ascorbic acid modified PURs at $-28{ }^{\circ} \mathrm{C}$ and glass transition temperatures obtained for obtained PURs

\begin{tabular}{llllr}
\hline Polyurethane symbol & Loss modulus/MPa & Storage modulus/MPa & Damping coefficient Tan $\delta$ & Tg/ ${ }^{\circ} \mathrm{C}$ \\
\hline PUR-1/HDI/AA0 & 203 & 549 & 0.40 & -28 \\
PUR-1/HDI/AA1 & 143 & 402 & 0.36 & -31 \\
PUR-1/HDI/AA2 & 80 & 291 & 0.29 & -35 \\
\hline
\end{tabular}
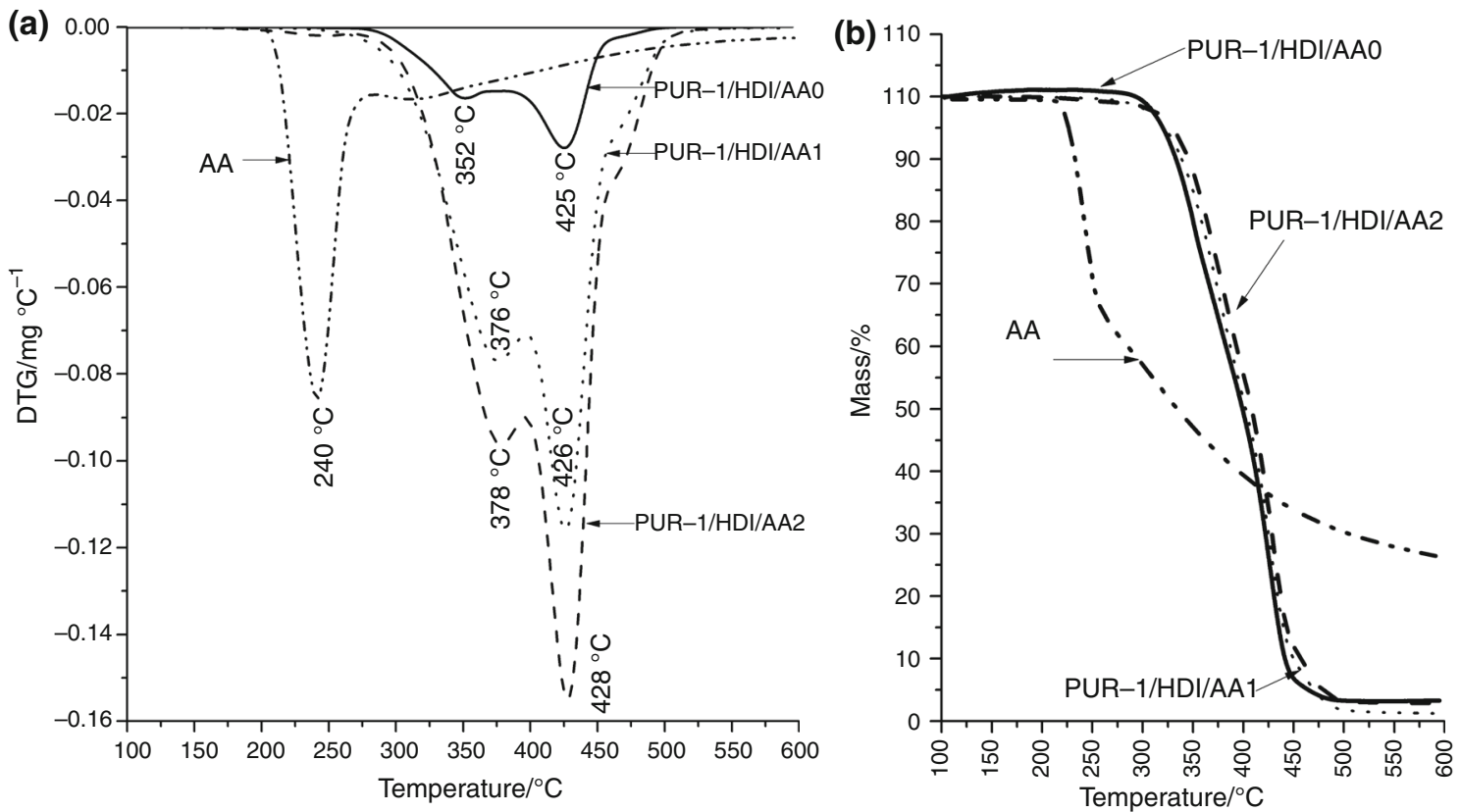

Fig. 3 DTG (a) and mass loss (b) curves for ascorbic acid (AA), unmodified (PUR-1/HDI/AA0) and modified with ascorbic acid (1 mass\%PUR-1/HDI/AA1 or 2 mass\%-PUR-1/HDI/AA2) polyurethanes

The indicated glass transition temperature $(\mathrm{Tg})$ of unmodified and modified with ascorbic acid (1 or 2 mass $\%)$ polyurethanes is presented in Table 3. A slight decrease in Tg was observed with an increase in the ascorbic acid content in the PUR matrix. That can be directly related to ascorbic acid behaving as an inactive filler in this PUR system. Noted glass transitions were between -28 and $-35^{\circ} \mathrm{C}$, what can be attributed to the $\mathrm{Tg}$ of the soft segments dHEBA [39, 40]. Studies, performed by Hassan et al., reported $\mathrm{Tg}$ of different polyester soft segments (made of poly(E-caprolactone), PCL) at $-33{ }^{\circ} \mathrm{C}$. Obtained in our study are $\mathrm{Tg}$ values comparable with the literature data concerning glass transition of poly(ester urethanes). The storage modulus (Fig. 2b) was lower for modified with ascorbic acid polyurethane samples in comparison with unmodified polyurethanes. Chattopadhyay et al. [39] related lower values of storage modulus with the lower tensile strength of the material. On the other hand, decrease in storage modulus and loss modulus with the increase in the filler amount was correlated interactions of modifier with
PUR matrix, which impact on the thermomechanical properties of obtained PURs [37, 40].

\section{Thermogravimetric analysis (TG)}

The results of the TG study are presented in Fig. 3. The thermogravimetric analysis of solid ascorbic acid indicated one-step degradation process (Fig. 3a). The degradation temperature of AA was indicated at $24{ }^{\circ} \mathrm{C}$. The 5 and $10 \%$ mass loss of AA was noted at 227 and $232{ }^{\circ} \mathrm{C}$, respectively, (Table 4). This temperature was lower than those reported for 5 and $10 \%$ mass loss of obtained PUR. In case of unmodified PUR $5 \%$ mass loss was observed at $319{ }^{\circ} \mathrm{C}$ and $10 \%$ mass loss at $330{ }^{\circ} \mathrm{C}$. Modification with 1 mass $\%$ of AA did not cause significant changes in temperature of $5 \%$ mass loss of the sample $\left(322{ }^{\circ} \mathrm{C}\right)$, but in case of $10 \%$ mass loss temperature it was higher of $10{ }^{\circ} \mathrm{C}$ in comparison with unmodified PURs $\left(340{ }^{\circ} \mathrm{C}\right)$. Application of 2 mass $\%$ of AA did not influence also the $5 \%$ mass loss of the sample observed at $330{ }^{\circ} \mathrm{C}$. For this sample noted $10 \%$ 
Table 4 Degradation temperatures noted for unmodified and ascorbic acid modified (1 or 2 mass\%) polyurethanes at Ist and IId stage of degradation process

\begin{tabular}{lllllll}
\hline PUR symbol & \multicolumn{2}{l}{ Degradation temperature $/{ }^{\circ} \mathrm{C}$} & & \multicolumn{2}{c}{ Mass } & loss $/ \%$ \\
\cline { 2 - 3 } \cline { 6 - 7 } & Stage I & Stage I & & 5 & 10 \\
\hline Solid AA & 240 & - & & 227 & 232 \\
PUR-1/HDI/AA0 & 376 & 426 & & 319 & 330 \\
PUR-1/HDI/AA1 & 352 & 425 & & 322 & 340 \\
PUR-1/HDI/AA2 & 378 & 428 & & 330 & 344 \\
\hline
\end{tabular}

mass loss was of $14^{\circ} \mathrm{C}$ higher in comparison with unmodified PURs $\left(344^{\circ} \mathrm{C}\right)$. Thus performed studies confirmed that AA is thermally stable up to approximately $190{ }^{\circ} \mathrm{C}$ what is comparable to Jingyan et al. [32] study. Reported $5 \%$ mass loss of the sample was comparable for unmodified and modified with 1 mass $\%$ of ascorbic acid polyurethanes. Evaluated temperatures were observed for $10 \%$ mass loss of the modified with 2 mass\% of AA PUR sample. Ascorbic acid influenced the thermal properties of obtained PURs.

The degradation of the obtained unmodified and ascorbic acid modified polyurethanes follows in two steps (Fig. 3), what is in contrary to AA. The degradation temperatures, indicated at both stages, for unmodified and ascorbic acid modified polyurethanes are presented in Table 4. Data analysis showed that both unmodified and modified polyurethanes are thermally stable up to approximately $250{ }^{\circ} \mathrm{C}$. It might be also noted that polyurethanes modified with 2 mass $\%$ of ascorbic acid had slightly elevated degradation temperatures, at both of its stages, in comparison with unmodified polyurethanes. This slight change might be caused by partial ascorbic acid incorporation into the polyurethane chain, which changes its chemical structure and its thermal properties [35]. On the other hand, a very small difference was detected between degradation temperatures of unmodified and modified with ascorbic acid polyurethanes.

\section{Conclusions}

In this study the characterization of mechanical and thermomechanical properties of unmodified and modified with ascorbic acid (1 or 2 mass $\%$ ) polyurethanes was performed. The FTIR and NMR spectroscopy revealed the formation of urethane bondings what was described in our previous work [33]. These studies indicated that part of ascorbic acid was incorporated into polyurethane chains, what disturb its chemical structure and the same its mechanical and thermal properties. The DMA analysis showed slight transition of loss modulus and tangent of an angle $\delta$ to lower temperature range caused by addition of ascorbic acid to the polyurethane matrix. The observed glass transition temperature was $-29{ }^{\circ} \mathrm{C}$ for PUR-1/ HMDI/AA0, $-31{ }^{\circ} \mathrm{C}$ for PUR-1/HMDI/AA1 and $-35{ }^{\circ} \mathrm{C}$ for PUR-1/HMDI/AA2. The decrease in Tg was observed with the increasing amount of ascorbic acid. Both unmodified and ascorbic acid modified polyurethanes were thermally stable up to approximately $250{ }^{\circ} \mathrm{C}$. Solid ascorbic acid was thermally stable up to $190{ }^{\circ} \mathrm{C}$ what is consistent with the literature data. The tensile strength and elongation at break was higher for unmodified polyurethanes. Addition of ascorbic acid modifier to the PURs chains caused a decrease in tensile strength and elongation at break of these materials. The hardness of obtained polyurethanes was higher for unmodified samples than for modified PURs, independently from the applied amount of ascorbic acid. The abrasion resistance slightly decreased with the amount of used ascorbic acid in polyurethane synthesis. Due to this it can be concluded that ascorbic acid, which was enclosed in PUR matrix, acted as an inactive filler, what caused the decrease in mechanical properties of obtained modified PURs. The mechanical and thermomechanical characteristics of the obtained unmodified and ascorbic acid modified polyurethanes are comparable with the literature data concerning biomedical polyurethane materials and may be suitable for applications in this field.

Open Access This article is distributed under the terms of the Creative Commons Attribution 4.0 International License (http://crea tivecommons.org/licenses/by/4.0/), which permits unrestricted use, distribution, and reproduction in any medium, provided you give appropriate credit to the original author(s) and the source, provide a link to the Creative Commons license, and indicate if changes were made.

\section{References}

1. Bakar M, Białkowska A, Szymańska J. Synthesis and evaluation of mechanical and thermal properties of segmented condensation polyurethanes Plastics. Rubber Compos. 2013;42(5):203-9.

2. Kucińska-Lipka J, Gubańska I, Janik H. Polyurethanes modified with natural polymers for medical application. Part I. Polyurethane/chitosan and polyurethane/collagen. Polimery. 2013;9:678.

3. Kucińska-Lipka J, Gubańska I, Janik H. Polyurethanes modified with natural polymers for medical application. Part II. Polyurethane/gelatin, polyurethane/starch, polyurethane/cellulose. Polimery. 2014;3:197.

4. Rogulska M, Kultys A, Lubczyk J. New thermoplastic polyurethane elastomers based on aliphatic-aromatic chain extenders with different content of sulfur atoms. J Therm Anal Calorim. 2015;121:397-410.

5. Pinto ERP, Barud HS, Polito WL, Ribeiro SJL, Messaddeq Y. Preparation and characterization of the bacterial cellulose/polyurethane nanocomposites. J Therm Anal Calorim. 2013;114:549-55.

6. Burke A, Hasirci N. Polyurethanes in biomedical applications. Biomaterials. Adv Exp Med Biol. 2004;553:83-101. 
7. Hsu-Chiang K, Chen-Chi M, Wei-Ping Ch. Synthesis, thermal, mechanical and rheological properties of multiwall carbon nanotube/waterborne polyurethane nanocomposite. Compos Sci Technol. 2005;65(11-12):1703-10.

8. Jiawen X, Yunhang L. Thermal and mechanical properties of polyurethane/montmorillonite nanocomposites based on a novel reactive modifier. Polym Degrad Stab. 2004;86(3):549-55.

9. patent US 4246360.

10. Der-Jang L. The relative physical and thermal properties of polyurethane elastomers: effect of chain extenders of bisphenols, diisocyanate, and polyol structures. J Appl Polym Sci. 1997; 66(7):1251-65.

11. Tien YI, Wei KH. Hydrogen bonding and mechanical properties in segmented montmorillonite/polyurethane nanocomposites of different hard segment ratios. Polymer. 2001;42:3213-21.

12. Kuan HC, Ma CCM, Chang WP, Yuen SM, Wu HH, Lee TM. Synthesis, thermal, mechanical and rheological properties of multiwall carbon nanotube/waterborne polyurethane nanocomposite. Compos Sci Technol. 2005;65(11):1703-10.

13. Wu G, Gu J, Zhao X. Preparation and dynamic mechanical properties of polyurethane-modified epoxy composites filled with functionalized fly ash particulates. J Appl Polym Sci. 2007; 105(3):1118-26.

14. Chern YC, Tseng SM, Hsieh KH. Damping properties of interpenetrating polymer networks of polyurethane-modified epoxy and polyurethanes. J Appl Polym Sci. 1999;74(2):328-35

15. Guelcher SA. Biodegradable polyurethanes: synthesis and applications in regenerative medicine. Tissue Eng Part B Rev. 2008;14(1):3-17.

16. Pnchuk L. A review of the biostability and carcinogenicity of polyurethanes in medicine and the new generation of "biostable" polyurethanes. J Biomater Sci Polym Ed. 1994;6(3):225-67.

17. Schubert MA, Wiggins MJ, DeFife KM, Hiltner A, Anderson JM. Vitamin $\mathrm{E}$ as an antioxidant for poly(etherurethane urea): in vivo studies. J Biomed Mater Res. 1996;32(4):493-504.

18. Juhasz M, Kitahara Y, Takahashi S, Fujii T. Thermal stability of vitamin $\mathrm{C}$ : thermogravimetric analysis and use of total ion monitoring chromatograms. J Pharm Biomed Anal. 2012;59:190.

19. Kannoujia DK, Kumar S, Nahar P. Covalent immobilization of ascorbate oxidase onto polycarbonate strip for L-ascorbic acid detection. J Biosci Bioeng. 2012;114:402.

20. Burini G. Development of quantitative method for the analysis of total L-ascorbic acid in foods by high-performance liquid chromatography. J Chromatogr A. 2007;1154:97.

21. Manabe R, Tsutsui K, Yamadda T, Kimura M, Nakano I, Shimono C, Sanzen N, et al. Transcriptome-based systematic identification of extracellular matrix proteins. Proc Natl Acad Sci. 2008; 105:12849.

22. Du M, Zhu Y, Yuan L, Liang H, Mou C, Li X, et al. Assembled 3D cell niches in chitosan hydrogel network to mimic extracellular matrix. Coll Surf A. 2013;434:78.

23. Zhang J, Doll BA, Beckman EJ, Hollinger JO. A biodegradable polyurethane-ascorbic acid scaffold for bone tissue engineering. J Biomed Mater Res Part A. 2003;67:389-400.

24. Zhang JY, Doll BA, Beckman EJ, Hollinger JO. Three-dimensional biocompatible ascorbic acid-containing scaffold for bone tissue engineering. Tissue Eng. 2004;9(6):1143-57.

25. Taoukis PS, Panagiotidis NG, Stoforos NG, Butz P, Fister H, Tauscher B. Kinetics of vitamin $\mathrm{C}$ degradation under high-presure-moderate temperature processing in model systems and fruit juices. In: Isaacs NS, editor. High pressure food science, bioscience and chemistry. The Royal Scociety of Chemistry; 1998. p. $310-316$.
26. Nisha P, Singhal RS, Pandit AB. A study on degradation kinetics of ascorbic acid in alma (Phyllanthus emblica L.) during cooking. Int J Food Sci Nutr. 2004;55:415.

27. Karhan M, Aksu M, Tetik N, Turhan I. Kinetic modeling of anaerobic thermal degradation of ascorbic acid in rose hip (Rosa canina L) pulp. J Food Qual. 2004;27:311.

28. Cruz RMS, Vieira MC, Silva CLM. Effect of heat and thermosonication treatments on watercress (Nasturtium officinale) vitamin C degradation kinetics. Innov Food Sci Emerg Technol. 2008;9:483.

29. Dhuique-Mayer C, Tbatou M, Carail M, Caris-Veyrat C, Dornier M, Amiot MJ. Thermal degradation of antioxidant micronutrients in citrus juices: kinetics and newly formed compounds. J Agric Food Chem. 2007;55:4209.

30. Burdurlu HS, Koca N, Karadeniz F. degradation of vitamin C in citrus juice concentrates during storage. J Food Eng. 2011; $74: 211$.

31. Shephard AB, Nichols SC, Braithwaite A. Moisture induced solid phase degradation of L-ascorbic acid part 3, structural characterisation of degradation products. Talanta. 1999;48:607.

32. Horagai Y, Hung L, Kimura Y, Adachi S. Decomposition and discoloration kinetics of L-ascorbic acid powders in superheated steam. LWT Food Sci Technol. 2008;41:2113.

33. Lerdkanchanaporn S, Dollimore D, Alexander KS. A thermogravimetric study of ascorbic acid and its excipients in pharmaceutical formulations. Thermochim Acta. 1996;284:115.

34. Jingyan S, Yuwen L, Zhiyong W, Cunxin W. Investigation of thermal decomposition of ascorbic acid by TG-FTIR and thermal kinetics analysis. J Pharm Biomed Anal. 2013;77:116.

35. Kucińska-Lipka J, Gubańska I, Janik H. L-ascorbic acid modified poly(ester urethane)s as a suitable candidates for soft tissue engineering applications. React Funct Polym. 2015;97:105-11534.

36. Cetina-Diaz SM, Chan-Chan LH, Vargas-Coronado RF, Cervantes-Uc JM, Quintana-Owen P, Paakinaho K, Kellomaki M, Di Silvio L, Deb S, Cauich-Rodríguez JV. Physicochemical characterization of segmented polyurethanes prepared with glutamine or ascorbic acid as chain extenders and their hydroxyapatite composites. J Mater Chem B. 2014;2(14):1966-76.

37. Ma Z, Hong Y, Nelson DM, Pichamuthu JE, Leeson CE, Wagner R. Biodegradable polyurethane ureas with variable polyester or polycarbonate soft segments: effects of crystallinity, molecular weight and composition on mechanical properties. Biomacromol. 2011;12:3265-74.

38. Guan J, Kazuro LF, Sacks MS, Wagner WR. Preparation and characterization of highly porous, biodegradable polyurethane scaffolds for soft tissue applications. Biomaterials. 2005; 26:3961-71.

39. Poręba R, Spirkova M, Brozova L, Lazic N, Pavlicevic J, Strachota A. Aliphatic polycarbonate-based polyurethane elastomers and nanocomposites. II. Mechanical, thermal and gas transport properties. J Appl Polym Sci. 2013;127:329-41.

40. Bogdanov B, Toncheva V, Schacht E. Thermal properties and morphology of poly(ester urethanes) prepared from polycaprolactone diol. J Therm Anal Calorim. 1999;56:1115-21.

41. Chattopadhyay DK, Sreedhar B, Raju KVSN. Influence of varying hard segments on the properties of chemically crosslinked moisture-cured polyurethane-urea. J Polym Sci Polym Phys. 2006;44:102-18.

42. Oprea S, Oprea V. Mechanical behaviour during different weathering tests of the polyurethane elastomers films. Eur Polym J. 2002;38:1205-10. 